\title{
Parallel Resonant DC Link Inverter for Thermoacoustic Power Genera- tion
}

\author{
Ma Li Li ${ }^{1,2, *}$ and Xia Jia Kuan ${ }^{2}$ \\ ${ }^{1}$ School of Information and Control Engineering, Liaoning Shihua University, Fushun, 113001, China \\ ${ }^{2}$ School of Electrical Engineering, Shenyang University of Technology, Shenyang, 110870, China
}

\begin{abstract}
A new parallel resonant soft-switching DC link inverter which can deal with the output power from thermoacoustic energy generation system is proposed. Auxiliary resonant unit is added to DC link to make DC bus voltage decreased to zero periodically, which realized all switches with zero voltage operation of in the inverter. The time of the duration for the DC bus zero voltage has nothing to do with the load current. The same bridge arm in the inverter is not made instantaneous short circuit and controlled reliably. Random duration of zero voltage was obtained through the on-off instant control of the auxiliary switch. Various flexible pulse width modulation strategies can be applied in the softswitching inverter. The topology structure is put forward and the circuit working principle is analyzed in this paper. The equivalent different working modes are analyzed and the mathematical equations are given. The principle of parameter design is put forward according to the circuit structure. The experiment is carried out and through it the validity and correctness of the theoretical analysis is proved.
\end{abstract}

Keywords: DC-link, parallel resonant, thermoacoustic power generation, zero-current turn off, zero-voltage turn on.

\section{INTRODUCTION}

Inverter technology is one of the basic power electronic transformation technologies, which has been widely used in various occasions. For example, the variable frequency speed regulation for the AC motor, uninterrupted power supply, motor braking energy feedback, solar power, geothermal power, wind power [1]. Since Dr Divan has put forward parallel resonant soft-switching DC-link soft switching inverter, researchers have proposed several improved structures [2-14]. In the paper [12] the topology structure is proposed that the large capacity electrolytic capacitor is in series in the DC bus. It make the neutral point potential be drifted in a lighter load condition. This will has effect the generation mechanism of DC link with zero voltage. The paper [13] proposed clamped resonant DC link inverter topology structure. The advantage is to reduce the resonance peak voltage and the defect is that the value still is higher than DC voltage to increase the voltage stress. In the paper [14] the topology structure is proposed is that the auxiliary switch device using is more, which makes the switch control complex and loss increase. According to the parallel resonant DC link inverter characteristics and overcome the above shortcomings. A new parallel resonant DC link inverter topology is proposed in this paper. The topology structure has the following characteristics. (1) The large capacitance is not in the DC bus, which cannot cause the neutral potential changes. (2) Random duration of zero voltage is obtained through the turning on instant control of one auxiliary switch. Various flexible pulse width modulation strategies could be applied in the soft-switching inverter. (3) The time of the duration for the DC bus zero voltage has nothing to do with the load current. The duration zero-voltage time has nothing with the resonant inductor setting current and depends only on the resonant component values. (4) The energy storage component is not in the DC bus, only one switch, making the loss smaller. (5) The same bridge arm in the inverter is not made instantaneous short circuit during the soft-switching and controlled reliably.

The topology structure is put forward and the circuit working principle is analyzed in this paper. The equivalent different working modes are analyzed and the mathematical carried out and through it the validity and correctness of the equations are given. The principle of parameter design is put forward according to the circuit structure. The experiment is theoretical analysis is proved.

\section{THE CIRCUIT STRUCTURE AND WORKING PRINCIPLE}

2.1. The Circuit Structure Link Inverter Circuit and Equivalent Circuit Structure are Shown in Fig. (1 and 2), Respectively

I Auxiliary resonant circuit; II PWM inverter;III Perceptual load; In order to simplify the analysis, make the following assumptions:

(1) All components in the circuit are ideal. 


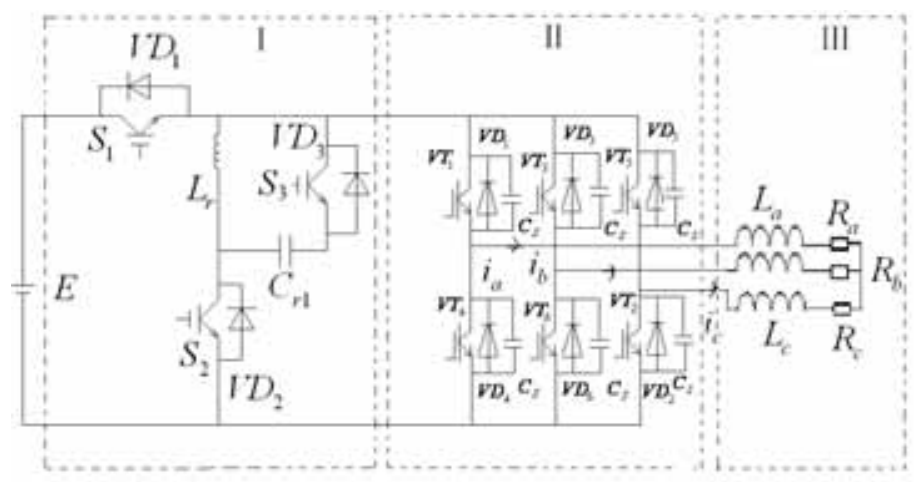

Fig. (1). Proposed three-phase parallel resonant DC link inverter.

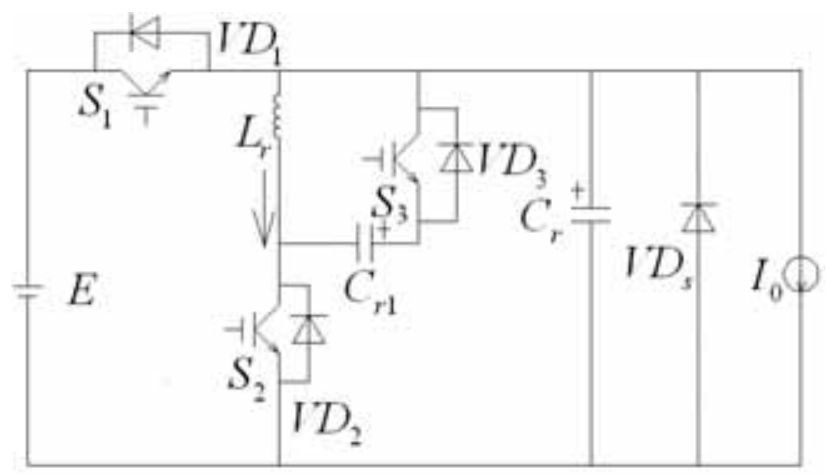

Fig. (2). Inverter equivalent circuit.

(2) The resonant inductance $L_{r}$ is far less than the load inductance, the resonant cycle is very short. The load current can be equivalent to a constant current source in a resonant switching cycle.

(3) The DC power supply voltage is an ideal voltage source.

(4) The parallel capacitance can be equivalent to $C_{r}=3 C_{s}$

The circuit structure is simple, and is composed of the DC power supply, the auxiliary circuit and the inverter circuit mainly. The auxiliary circuit includes the resonant inductance $\mathrm{L}_{\mathrm{r}}$, the resonant capacitance $\mathrm{C}_{\mathrm{r}}, \mathrm{C}_{\mathrm{r} 1}$, three switches $\mathrm{S}_{1}, \mathrm{~S}_{2}, \mathrm{~S}_{3}$ and the diode $\mathrm{VD}_{1}, \mathrm{VD}_{2}, \mathrm{VD}_{3}$. The voltage and current direction in figure are defined as the positive direction.

\subsection{The Working Principle}

Different working model of equivalent circuits are shown in Fig. (3). The designed circuit during a switching cycle is divided into seven working modes. The whole circuit waveforms are shown in Fig. (4).

Mode $1 t_{0}-t_{1}$ : At $t_{0}$ the switch $S_{1}$ is in the conducting state. The switches $S_{2}$ and $S_{3}$ are turned off. The current and the energy through the switching $S_{1}$ flow from the power voltage $\mathrm{E}$ to the load. The circuit is in a stable conducting state and the resonant circuit does not work. The inductor current $\mathrm{L}_{\mathrm{r}}$ is zero and the capacitor voltage $\mathrm{C}_{\mathrm{r}} 、 \mathrm{C}_{\mathrm{r} 1}$ is $\mathrm{E}$, zero respective ly at $\mathrm{t}_{0}$. The duration time depends on the $\mathrm{AC}$ output voltage needed by PWM controlling of the inverter circuit waveform duration time.

Mode $2 t_{1}-t_{2}$ : The switch $S_{2}$ is added to the drive signal. The switch $S_{2}$ is turned on with the zero current because of inductance $\mathrm{L}_{\mathrm{r}}$. The inductor current is increased linearly, and is Ia at $t_{2}$. The aim of the desired current have enough energy to maintain $\mathrm{L}_{\mathrm{r}}, \mathrm{C}_{\mathrm{r}}$ resonant circuit to finish resonance process. The expressions

$$
\begin{aligned}
& \frac{d i_{L r}(t)}{d t}=\frac{E}{L_{r}} \\
& u_{C r}(t)=E \\
& \Delta t_{1}=t_{2}-t_{1}=\frac{L_{r} I_{a}}{E}
\end{aligned}
$$

Mode $3 t_{2}-t_{3}$ : The switch $S_{1}$ is turned off at $t_{2}$. The switch $S_{1}$ is turned off with zero voltage, because the capacitance $C_{r}$ voltage is $E$. The switch $S_{1}$ is turned off, at the meantime, the resonant circuit starts to resonate. In this process, the capacitance $\mathrm{C}_{\mathrm{r}}$ discharges. The capacitance $\mathrm{C}_{\mathrm{r}}$ provides the current not only for the load but also the inductance. The inductor current is added to the maximum $\mathrm{I}_{\mathrm{m}}$ and the capacitor $\mathrm{C}_{\mathrm{r}}$ voltage is zero at $\mathrm{t}_{3}$. The expressions

$$
i_{L}(t)=\left(I_{a}+I_{0}\right) \sin \omega_{1}\left(t-t_{2}\right)+\frac{E}{Z_{1}} \cos \omega_{1}\left(t-t_{2}\right)-I_{0}
$$




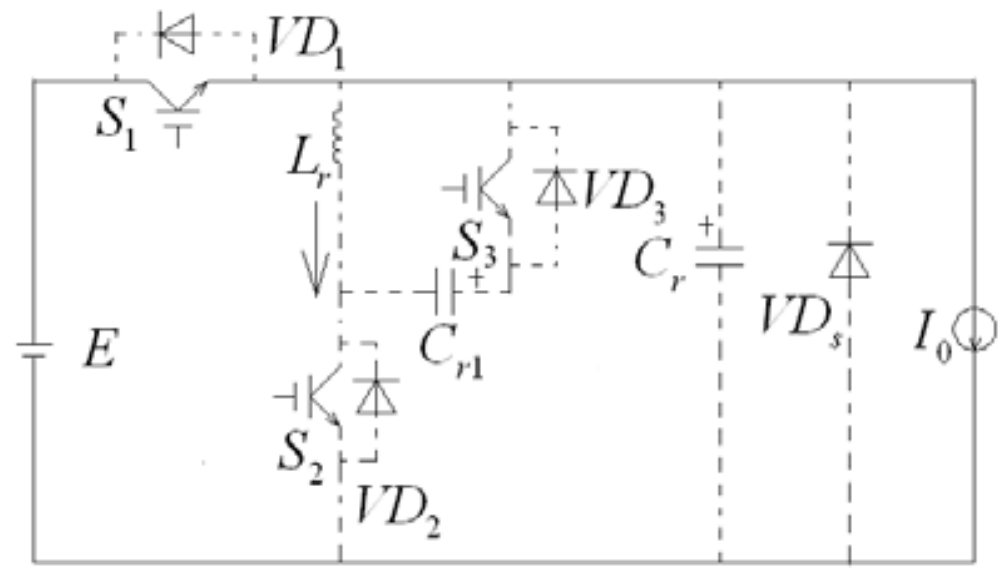

(a) Mode 1

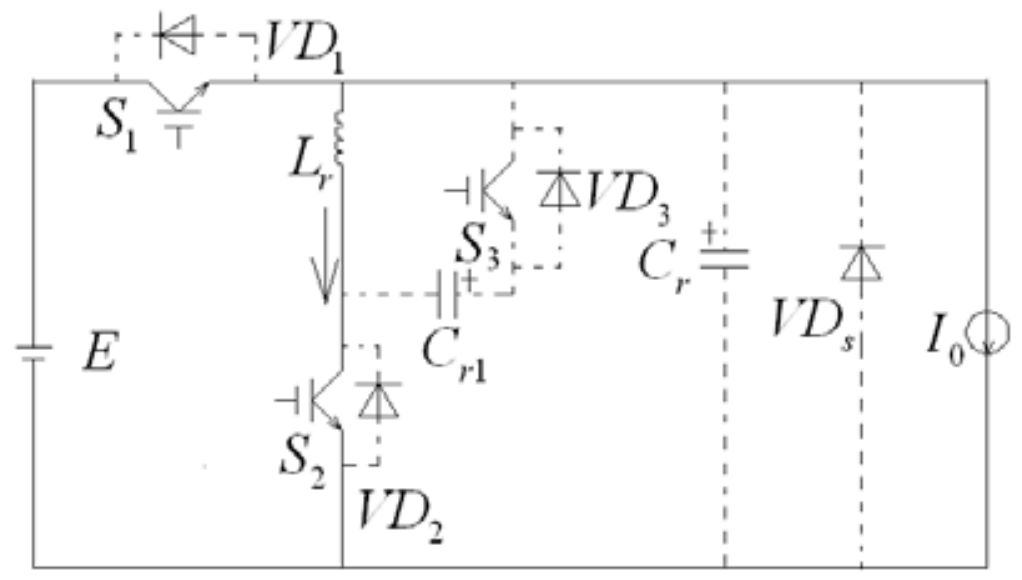

(b) Mode 2

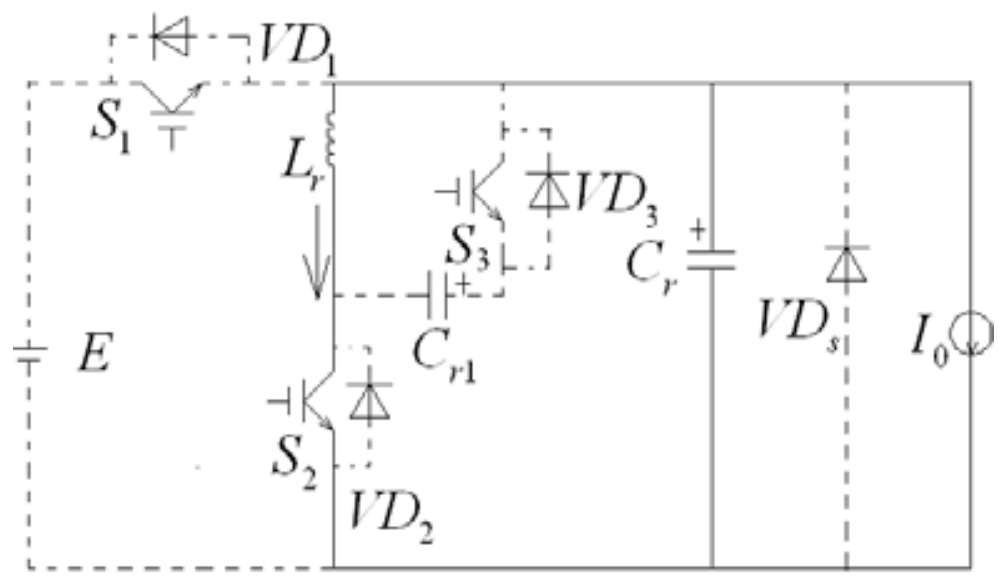

(c) Mode 3

Fig. (3). Contd... 


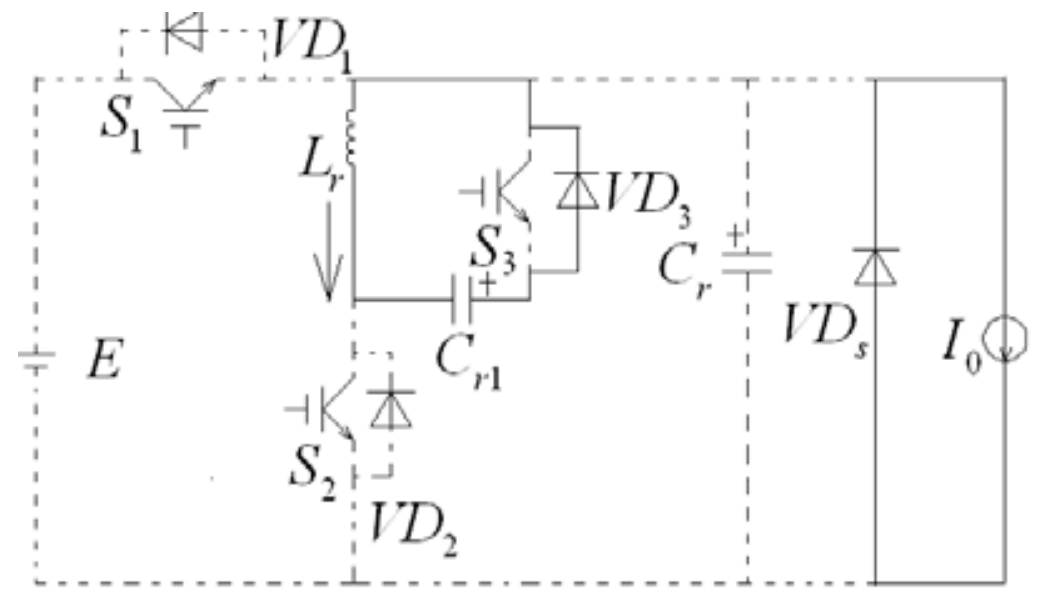

(d) Mode 4

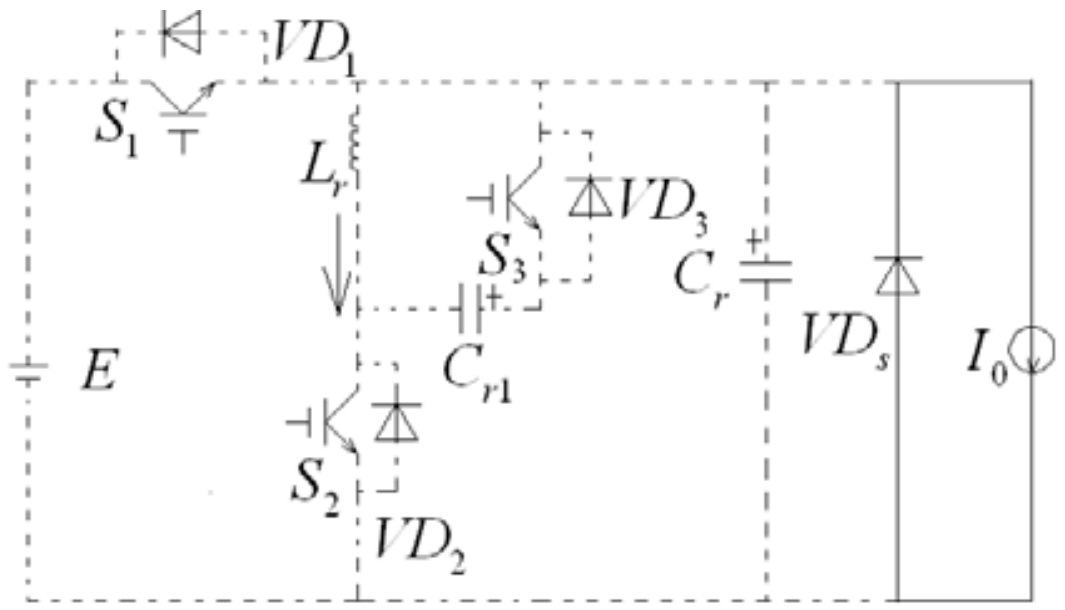

(e) Mode 5

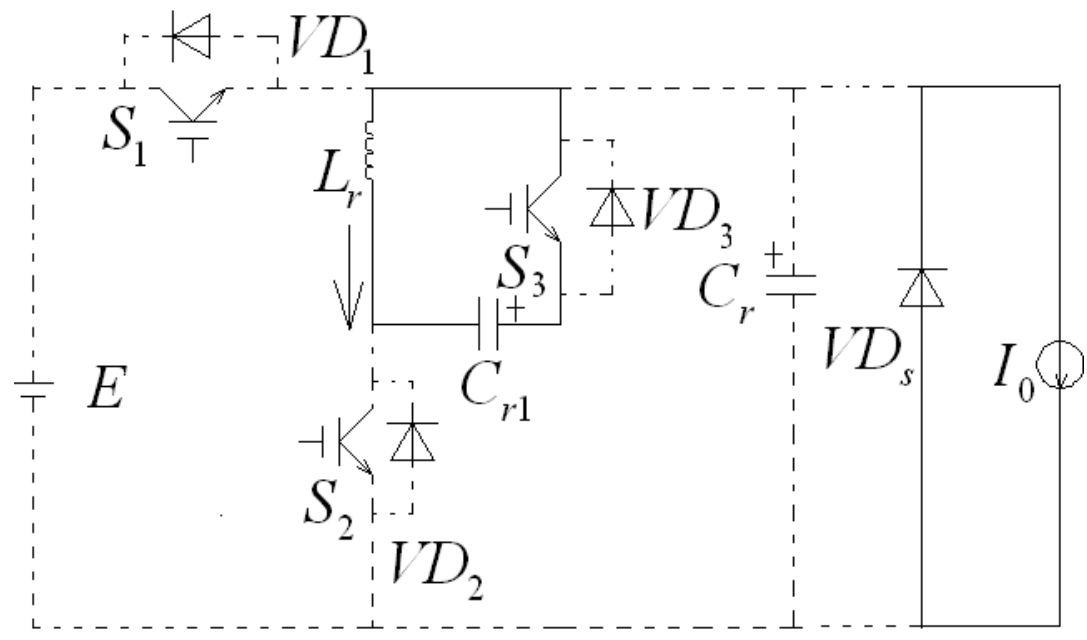

(f) Mode 6

Fig. (3). Contd... 


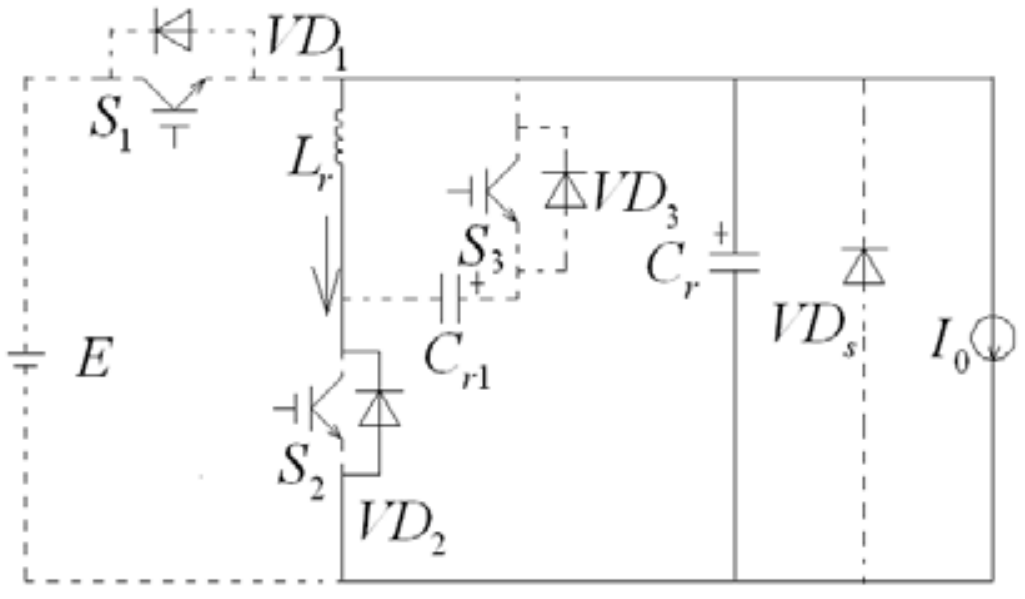

(g) Mode 7

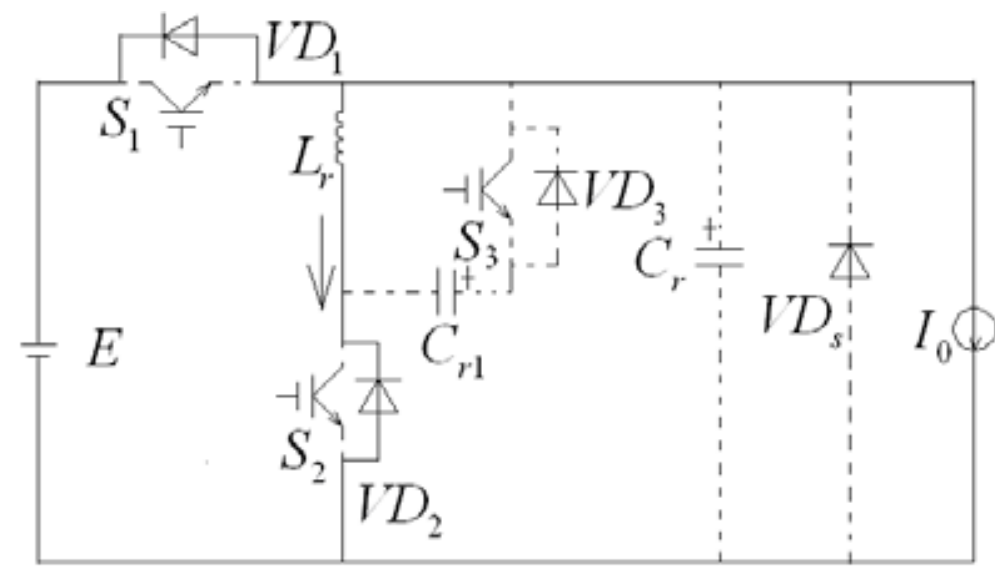

(h) Mode 8

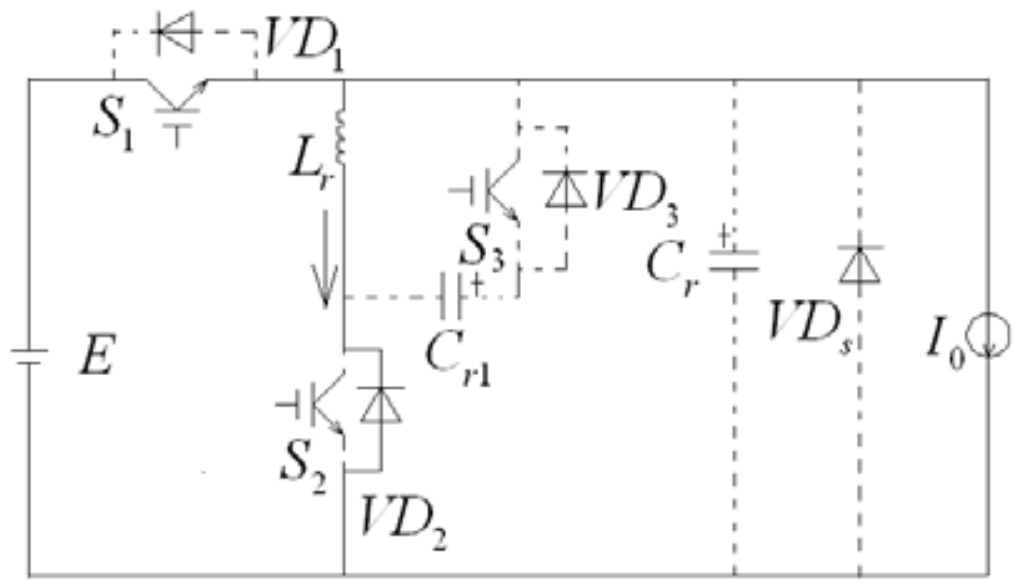

(i) Mode 9

Fig. (3). Action mode circuit. 


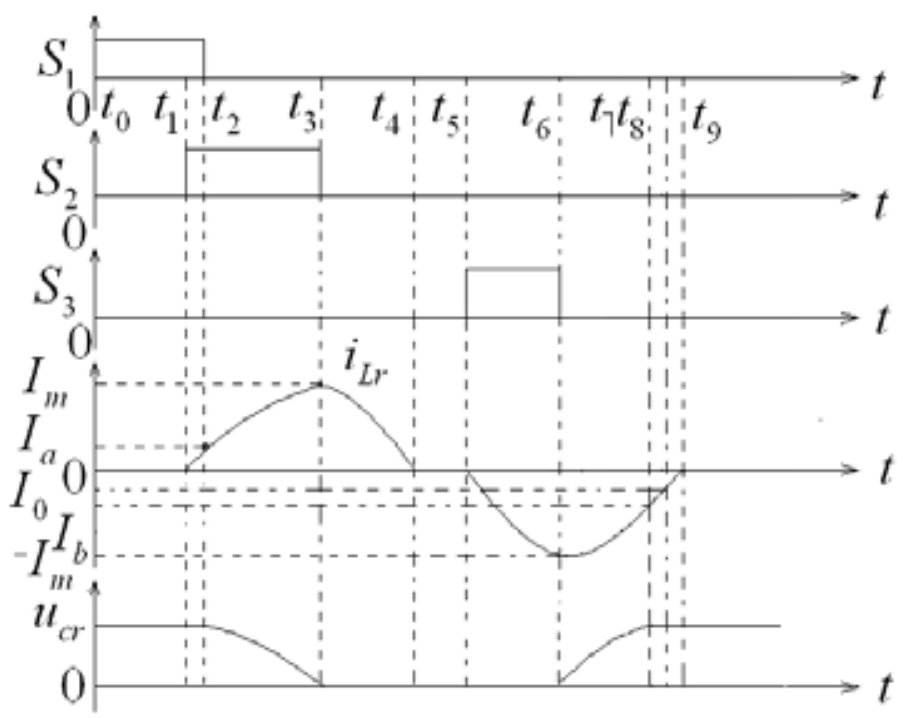

Fig. (4). Inverter waveform.

$u_{c r}(t)=E \cos \omega_{1}\left(t-t_{2}\right)-Z_{1}\left(I_{a}+I_{0}\right) \sin \omega_{1}\left(t-t_{2}\right)$

$\Delta t_{2}=t_{3}-t_{2}=\frac{1}{\omega_{1}} \arctan \frac{E / Z_{1}}{I_{a}+I_{0}}$

$\omega_{1}=\frac{1}{\sqrt{L_{r} C_{r}}}, Z_{1}=\sqrt{\frac{L_{r}}{C_{r}}}$

Mode $4 t_{3}-t_{4}$ : The diode $V_{3}$ is turned on with zero voltage because the switch $S_{2}$ is not conducted. Then the inductance $L_{r}$ and the capacitance $C_{r 1}$ begin in resonance. The capacitor $\mathrm{C}_{\mathrm{r} 1}$ voltage is added to $-\mathrm{E}_{1}$ and the inductor current is reduced to zero at $t_{4}$. The DC bus voltage is zero and the diode $\mathrm{VD}_{\mathrm{S}}$ is in the conduction. The current flows the load through the diode $\mathrm{VD}_{\mathrm{S}}$. The expressions

$i_{L r}(t)=I_{m} \cos \omega_{2}\left(t-t_{3}\right)$

$u_{C r 1}(t)=Z_{2} I_{m} \sin \omega_{2}\left(t-t_{3}\right)$

$\Delta t_{3}=t_{4}-t_{3}=\frac{\pi}{2 \omega_{2}}$

$\omega_{2}=\frac{1}{\sqrt{L_{r} C_{r 1}}}, Z_{2}=\sqrt{\frac{L_{r}}{C_{r 1}}}$

Mode $5 t_{4}-t_{5}$ : The diode $V_{3}$ is turned off with zero current because the inductor current is zero. The length of this period of time can set arbitrarily according to when the main switches of the inverter circuit need and at any time the switch $\mathrm{S}_{3}$ may be turned on. The period of time is $\triangle$ Trandom

Mode $6 t_{5}-t_{6}$ : The switch $S_{3}$ is added to the drive signal. The switch $S_{3}$ is turned on with zero voltage because the diode $\mathrm{VD}_{3}$ is in the conduction. After the switch $\mathrm{S}_{3}$ is turned on, the inductance $\mathrm{L}_{\mathrm{r}}$ and the capacitance $\mathrm{C}_{\mathrm{r} 1}$ begin in resonance. The capacitor $\mathrm{C}_{\mathrm{r} 1}$ voltage reduces and the inductor current increases gradually. The inductance $\mathrm{L}_{\mathrm{r}}$ and the switch
$\mathrm{S}_{3}$ are formed discharge circuit. The inductor current is $-\mathrm{I}_{\mathrm{m}}$ at $t_{6}$. The capacitor $C_{r 1}$ voltage is zero. The load current flows through the diode $\mathrm{VD}_{\mathrm{S}}$. Turn on the main switches of the inverter circuit with zero voltage in this process. The expressions

$$
\begin{aligned}
& i_{L r}(t)=\frac{-E_{1}}{Z_{2}} \sin \omega_{2}\left(t-t_{5}\right) \\
& u_{C r 1}(t)=-E_{1} \cos \omega_{2}\left(t-t_{5}\right) \\
& \Delta t_{5}=t_{6}-t_{5}=\frac{\pi}{2 \omega_{2}}
\end{aligned}
$$

Mode $7 t_{6}-t_{7}$ : The switch $S_{3}$ is turned off with zero voltage. The diode $\mathrm{VD}_{2}$ is conducted and the inductance and the capacitance begin the resonance. The inductor current decreases and the capacitor $C_{r}$ voltage increases gradually. The parts of inductor current supply for the load and the other parts are in resonance with the capacitance $C_{r}$. The inductor current is $\mathrm{I}_{\mathrm{b}}$ and the capacitor $\mathrm{C}_{\mathrm{r}}$ voltage is $\mathrm{E}$ at $\mathrm{t}_{7}$. The resonance process is over. The expressions

$$
\begin{aligned}
& i_{L r}(t)=\left(I_{m}-I_{0}\right) \cos \omega_{1}\left(t-t_{6}\right)-I_{0} \\
& u_{C r}(t)=\left(I_{m}-I_{0}\right) Z_{1} \sin \omega_{1}\left(t-t_{6}\right) \\
& \Delta t_{6}=t_{7}-t_{6}=\frac{1}{\omega_{1}} \arcsin \frac{E / Z_{1}}{I_{m}-I_{0}}
\end{aligned}
$$

Mode $8 \mathrm{t}_{7}-\mathrm{t}_{8}$ : The diode $\mathrm{VD}_{1}$ is turned on with zero voltage because of the DC bus voltage $\mathrm{E}$ at $\mathrm{t}_{7}$. The inductor current supplies the power for the load and the rest of the current feeds back to the power supply through the diode $\mathrm{VD}_{1}$ at the same time. The inductor current linearly decreases and is $\mathrm{I}_{0}$ at $\mathrm{t}_{8}$. The expressions

$$
\begin{aligned}
& i_{L r}\left(t_{7}\right)=I_{b} \\
& u_{c r}\left(t_{7}\right)=E
\end{aligned}
$$




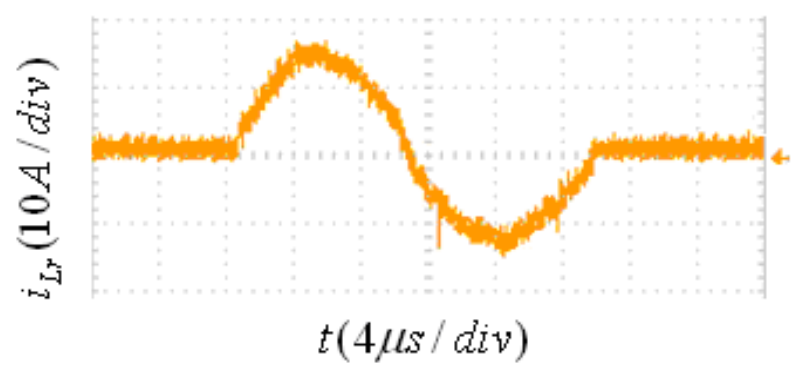

Fig. (5). Resonant inductance $\mathrm{L}_{\mathrm{r}}$ current waveform.

$u_{c r 1}\left(t_{7}\right)=0$

$\Delta t_{7}=t_{8}-t_{7}=\frac{L_{r}\left(I_{b}-I_{0}\right)}{E}$

Mode $9 t_{8}-t_{9}$ : The switch $S_{1}$ is turned on with zero voltage at $t_{8}$. The power source and the inductance supply the power for the load together. The inductor current linearly decreases and is zero at $t_{9}$. The whole process is over. The expressions

$i_{L r}\left(t_{8}\right)=I_{0}$

$u_{c r}\left(t_{8}\right)=E$

$u_{c r 1}\left(t_{8}\right)=0$

$\Delta t_{8}=t_{9}-t_{8}=\frac{L_{r} I_{b}}{E}$

\section{THE CONDITION AND CONTROLLING STATEGY OF THE SOFT SWITH IMPLEMENTATION}

\subsection{The Condition the Soft Swith Implementation}

Based on the above work mode analysis, all the main switches of the inverter can be turned on with zero voltage. The set value of the inductor current is $I_{a}>\frac{E}{Z_{1}}-I_{0}$. According to the work mode analysis, if DC bus voltage can be $\mathrm{E}$ through the resonance, the resonant inductance should have enough pre-charge current and current peak value. In order to achieve the soft -switching in the whole process, the inductance current set value the resonant current peak value, the load current value and the capacitance voltage value must be detected during the working process. The current voltage and resonant circuit element parameters meet the above conditions.

\subsection{The Control Strategy}

The control system is made up of the auxiliary resonant controlling circuit and the main controlling circuit of the inverter. The work of the resonant circuit is to provide the condition for the switches of the inverter which is turned on and turned off with zero voltage. When the switch VTs need to change the status, it need lag for a while to switch. This is dead zone time for the hard switching inverter. This is less than the time of the DC bus zero voltage. When the switch $S_{1}$ is in normal conduction, the switches VTs of the inverter are not in the action state. Before the switch $S_{1}$ is turned off, the switch $S_{2}$ is turned on. The resonant inductance current value is detected and the set value is made. What to do can ensure the resonant inductance have enough energy to complete all the resonant process. Turn off the switch $S_{1}$ and detect the DC link voltage. When the DC link voltage value is zero, the switch $\mathrm{S}_{3}$ will be turned on and the switches in the inverter begin to act. Before the switch $\mathrm{S}_{3}$ be turned on, there is period of random time $\triangle$ Trandom. The turning-on the switch $S_{3}$ is controlled automatically at the moment the inverter needs to act. Random duration of zero voltage is obtained through the turning on instant control of one auxiliary switch. Random duration of zero voltage is chosen by in the softswitching inverter controlled strategies. Various flexible pulse width modulation strategies could be applied in the soft-switching inverter. After the inverter completed the switches work and the DC link voltages naturally be changed the DC supply voltage. The DC link voltage is detected. When the DC link voltage value fall to zero and rise to $\mathrm{E}$, it is equal to the power voltage and the switch $S_{1}$ is turned on with zero voltage. According to mode 4 mode 5 and mode 6 , the time of the DC bus zero voltage can be calculated.

$$
T_{\text {zero }}=\Delta t_{4}+\Delta t_{\text {random }}+\Delta t_{5}=\Delta t_{\text {random }}+\frac{\pi}{\omega_{2}}
$$

\section{THE EXPERIMENTAL RESULTS AND ANALYSIS}

In order to verify the effectiveness of the proposed circuit theory analysis, the hardware circuit structure is built and the experiment has been carried on. the working parameters as follows: the switching frequency $10 \mathrm{KHZ}, \mathrm{L}_{\mathrm{r}} 70 \mathrm{uH}, \mathrm{C}_{\mathrm{s}} 33 \mathrm{nF}$, $\mathrm{C}_{\mathrm{r} 1} 91 \mathrm{nF}, \mathrm{E} 300 \mathrm{~V}$.The measured experiment waveform is shown in Figs. (5-13). It can be seen that the DC bus voltage drop to zero, then back up to $\mathrm{E}$ and the zero voltage grooves is formed. The resonant capacitor $C_{r}$ is the DC bus voltage. When the resonance capacitance $\mathrm{C}_{\mathrm{r}}$ voltage is zero in the resonance process, all the switches in the inverter bridge can be realized easily to switch with zero voltage. At this moment the current of the resonant inductance $\mathrm{L}_{\mathrm{r}}$ is the 


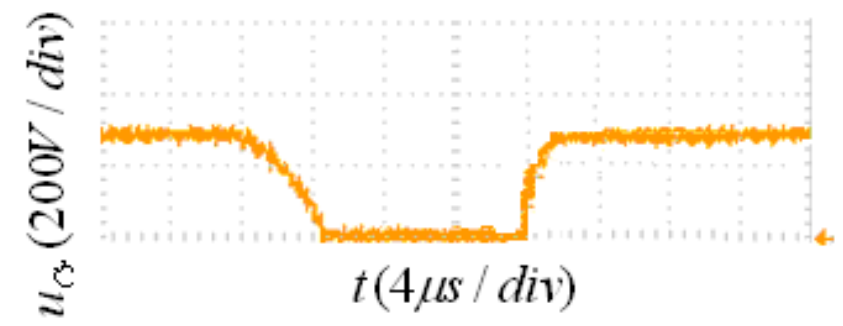

Fig. (6). Capacitor $\mathrm{C}_{\mathrm{r}}$ voltage waveform.

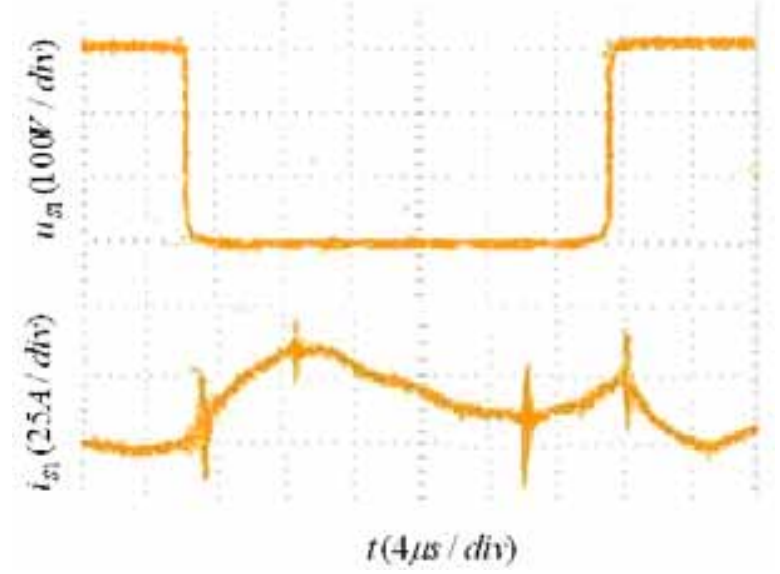

Fig. (7). Terminal voltage and the current waveform when the switch $S_{1}$ is turned on and turned off in the hard switching condition.

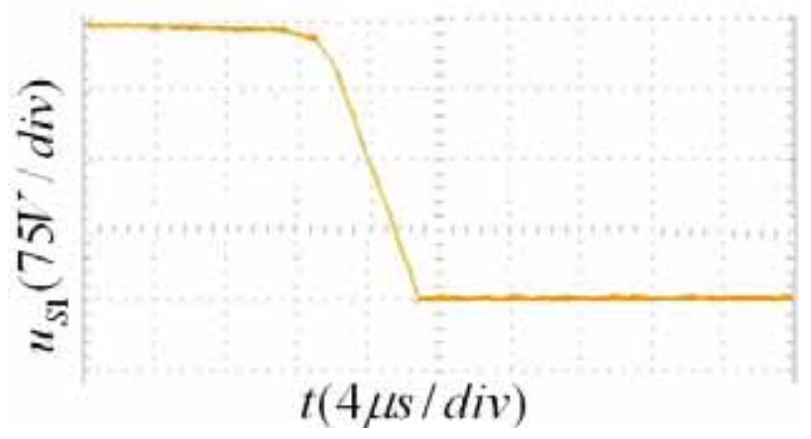

Fig. (8). Terminal voltage waveform when the switch $S_{1}$ is turned on in the soft switching condition.

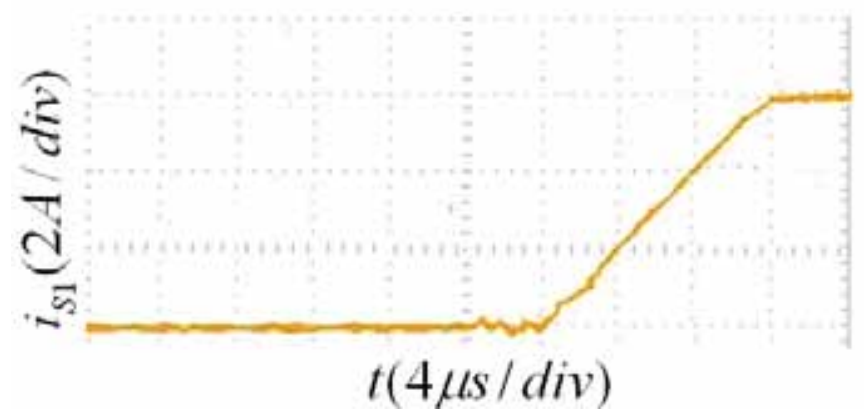

Fig. (9). Terminal voltage waveform when the switch $S_{1}$ is turned on in the soft switching condition. 


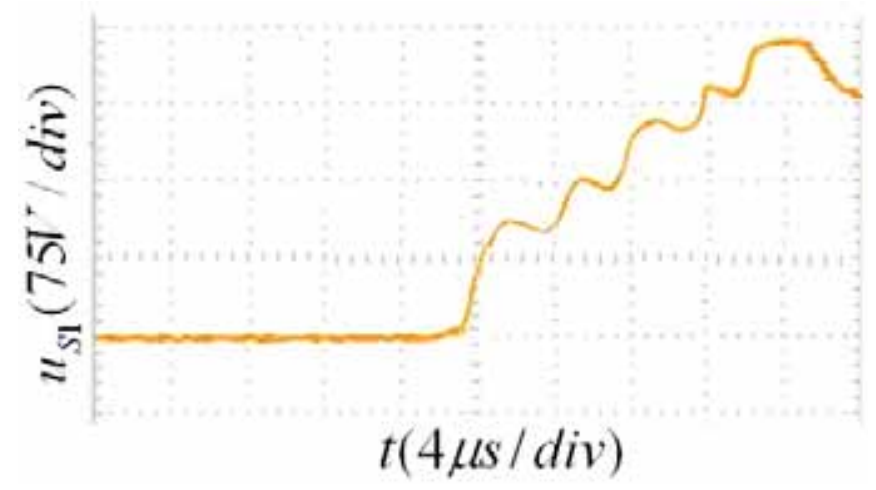

Fig. (10). Terminal voltage waveform when the switch $S_{1}$ is turned off in the soft switching condition.

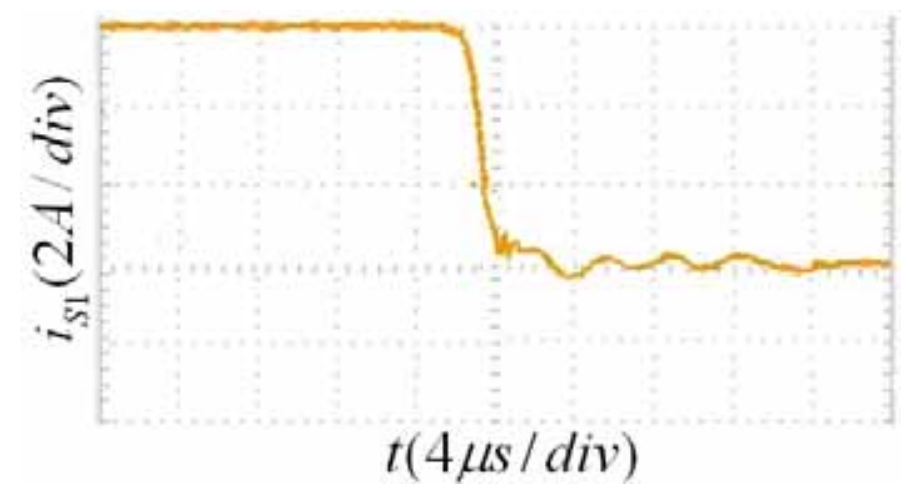

Fig. (11). Current when the switch $S_{1}$ is turned off in the soft switching condition.

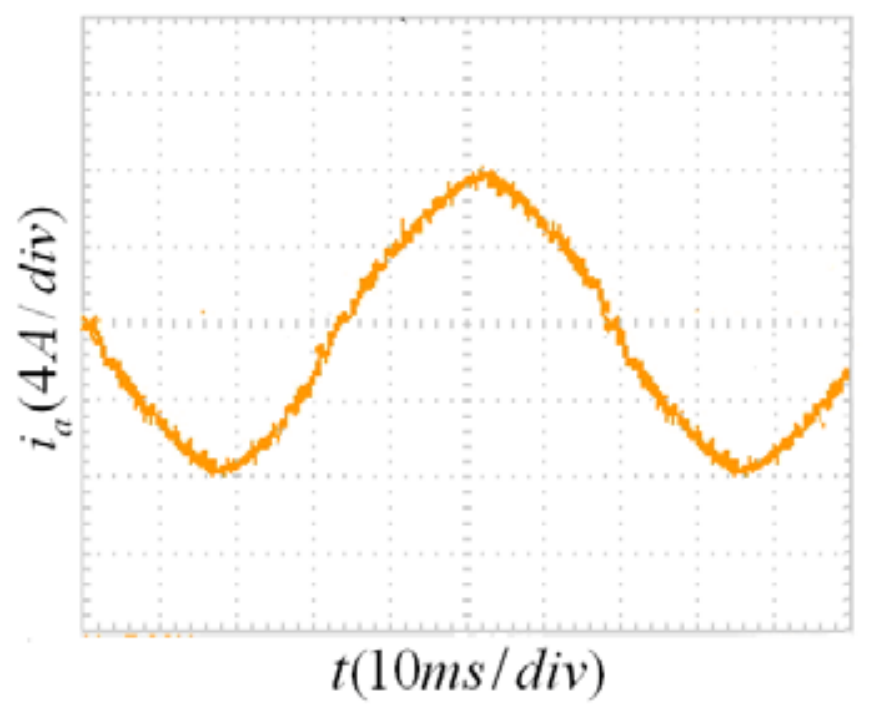

Fig. (12). Phase A current waveform is in the soft switching.

maximum $I_{m}$, the length of the period with zero voltage switching can be controlled by the resonant parameters $\mathrm{L}_{\mathrm{r}}$, $\mathrm{C}_{\mathrm{r} 1}$. After the process for three switches in the inverter bridge with zero voltage is finished, the current maximum of the resonant inductance is $-\mathrm{I}_{\mathrm{m}}$. With the resonance, the voltage value of the resonant capacitor $C_{r}$ is $E$. The rest inductance current through the diode flow back to the power voltage in
Fig. $(\mathbf{5}, \mathbf{6})$. The whole process is over. It can be seen from the Fig. (7) that under the hard switch condition, when the switch $\mathrm{S}_{1}$ is turned and off, the change rate of the voltage and the current are very obvious, the peak and the oscillation emerge, and the big loss is made in the switch process. It can be seen from the Fig. $(\mathbf{8 , 9})$ that due to the effect of resonance capacitance $C_{r}$, the switch $S_{1}$ is turned on with the zero 


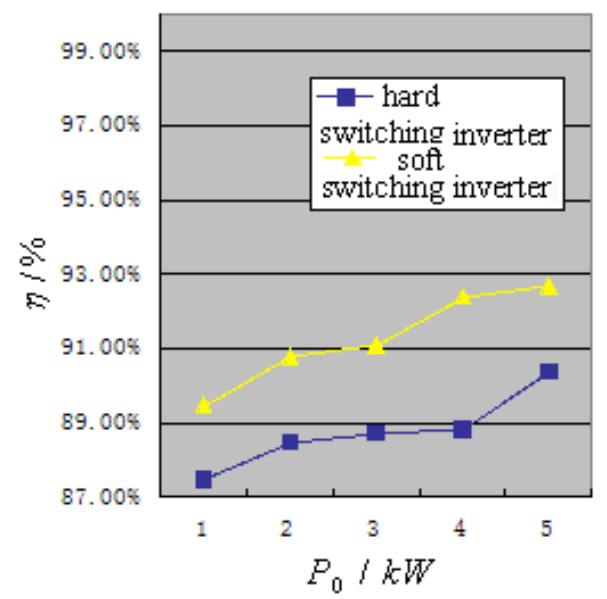

Fig. (13). Efficiency curve.

voltage and the rate change of the voltage is very weakly. It can be seen from the Fig. $(\mathbf{1 0}, \mathbf{1 1})$ that due to the effect of resonance capacitance $\mathrm{Cr}$, the switch $\mathrm{S} 1$ is turned off with the zero voltage, the rate change of the current is very weakly. Compared with the hard switching condition, the switching loss is very small and the designed circuit is rational. The output phase A current waveform is smooth and has no oscillation phenomenon. The output power quality is stable, as shown in Fig. (12). The parallel resonant DC link inverter efficiency in the hard switching and soft switching conditions was tested respectively, as shown in Fig. (13), in the article. It can be seen that the efficiency under the condition of soft switch inverter is obvious higher than that of hard switching condition.

\section{CONCLUSION}

A new parallel resonant DC link soft switch inverter is put forward in this paper. The following conclusions are come to from the experiment. (1) The DC bus voltage can fall to the zero through the auxiliary resonant circuit periodically and the sustained maximum voltage is E. Which overcome the problem of the resonant capacitance instantaneous withstand the peak voltage higher than the dc power supply voltage when the bus voltage from zero rises. (2) The inverter output phase current sine wave is smooth without distortion. (3) Compared with hard switch inverter, efficiency is greatly enhanced. (4) The soft switching inverter is suitable for medium and small power field. Through the above prove is that the result of the experiment is good consistency with the theoretical analysis.

\section{CONFLICT OF INTEREST}

The authors confirm that this article content has no conflict of interest.

\section{ACKNOWLEDGEMENTS}

The research is financially supported by the National Science Foundation of China under Contract No.50977058.
Research for the Design of the New Hybrid Excitation Linear Generator and the Optimal Control Strategy of the Efficiency in Thermoacoustic System.

\section{REFERENCES}

[1] Y. Jimin, L. Xiaoling, and W. Jianguo, "Soft-switching technology ofgrid-connected photovoltaic system," Electric Power Automation Equipment, vol. 30, no. 9, pp. 85-88, 2010.

[2] G. Yilei, C. Shijie, and L. Zhengyu, "Strategy for single switch DC/DC converters to achieve softswitching," In: Proceedings of the CSEE, vol. 24, no. 11, pp. 130-133, 2004 (in Chinese).

[3] L. Jianwu, Z. Qionghua, and D. Qiong, "Study of a novel softswitching converter for switched reluctance motor," In: Proceedings of the CSEE, vol. 25, no. 17, pp. 142-149, 2005 (in Chinese).

[4] Z. Chunjiang, L. Yanmin, and W. Weiyang, "Optimal choice of SVPWM waves for soft-switched AC/DC rectifier," In: Proceedings of the CSEE, vol. 20, no. 6, pp. 35-38, 2000 (in Chinese).

[5] K. Jian-hong, H. Lei, D. Yan, and H. Xiang-ning, "Theory and applications of the compositesoft-switching power converters," Acta Electronica Sinica, vol. 29, no. 11, pp. 1571-1574, 2001. (in Chinese)

[6] H. Yuyao, W. Weigen, and X. Demin, "Principle, analysis, modeling and simulation of a three-phase DC-AC series-parallel resonant converter," In: “Proceedings of the CSEE," vol. 19, no. 12, pp. 14$17,1999$.

[7] M. Zhengfeng, N. Guangzheng, and Z. Wenyun, "Study of neutralpoint voltage unbalancing problem in DC-rail ZVT inverter," Transactions of China Electrotechnical Society, vol. 19, no. 5, pp. 81-86, 2004.

[8] Y. Jianhong, Z. Yanhong, and L. Jicheng, "Full-bridge phase-shift PWM ZVZCS converter," Electric Power Automation Equipment, vol. 30, no. 1, pp. 66-70, 2010.

[9] C. Guocheng, S. Chengbo, and Z. Linglan, "The analysis of a novel ZVS resonant DC-link inverter topology," Transactions of China Electrotechnical Society, vol. 16, no. 4, pp. 50-55, 2001 (in Chinese).

[10] Z. Dehua, Y. Jianping, and L. Teng, "Analysis and design of twoamplitude actively clamed resonant DC-link inverter," In: Proceedings of the CSEE, vol. 22, no. 9, pp. 48-53, 2002 (in Chinese).

[11] Z. Dehua, W. Fanbin, and L. Teng, "A novel two-amplitudecontrol strategy for seriesactively clamped resonant DC-link inverter," In: Proceedings of the CSEE, vol. 22, no. 7, pp. 7-12, 2002 (in Chinese).

[12] Q. Xiaolei, and R. Xinbo, "A novel two-amplitude active clamped resonant DC link inverter," In: Proceedings of the CSEE, vol. 28, no. 27, pp. 42-47, 2008 (in Chinese). 
[13] Y. Yinghua, X. Shunyi, and Z. Qi, "A novel DC link parallel resonant soft switching inverter," In: Proceedings of the CSEE, vol. 28, no. 12, pp. 50-54, 2008 (in Chinese).
[14] W. Jun, and X. Longxiang, "Application of power amplifier for active magnetic bearing using soft-switchingtechnology," Transactions of China Electrotechnical Society, vol. 24, no. 6, pp. 85-90, 2009 (in Chinese).

Received: October 16, 2014

Revised: December 02, 2014

Accepted: December 07, 2014

(C) Li and Kuan; Licensee Bentham Open.

This is an open access article licensed under the terms of the Creative Commons Attribution Non-Commercial License (http://creativecommons.org/licenses/by$\mathrm{nc} / 3.0 /$ ) which permits unrestricted, non-commercial use, distribution and reproduction in any medium, provided the work is properly cited. 